\title{
A Review on Survivin as a Prognostic and Therapeutic Cancer Biomarker
}

\author{
Amal Ahmed Ismail \\ Unaizah College of Pharmacy, Qassim University, Unaizah, KSA \\ Email: amal.zumrawy2012@gmail.com
}

How to cite this paper: Ismail, A.A. (2018) A Review on Survivin as a Prognostic and Therapeutic Cancer Biomarker. Open Journal of Pathology, 8, 15-23.

https://doi.org/10.4236/ojpathology.2018.8 1002

Received: December 4, 2017

Accepted: December 26, 2017

Published: December 29, 2017

Copyright $\odot 2018$ by author and Scientific Research Publishing Inc. This work is licensed under the Creative Commons Attribution International License (CC BY 4.0).

http://creativecommons.org/licenses/by/4.0/

(c) (i) Open Access

\begin{abstract}
Survivin is an antiapoptotic protein expressed in tumor cells that correlates with aggressiveness, prognosis and treatment. Objective: This review summarizes significance of survivin expression among different tumor types highlighting the potential value of survivin as an important biomarker that may have an impact on patient's response to therapy with prognostic implications.
\end{abstract}

\section{Keywords}

Survivin, Prognostic Biomarker, Cancer, Antiapoptotic

\section{Introduction}

The antiapoptotic survivin is a $16.5 \mathrm{kD}$ wild-type protein consisting of $142 \mathrm{ami}-$ no acids in length encoded by the BIRC5 gene at chromosome 17 [1] and it is expressed in fetal tissue and tumor cells [2]. The caspases (cysteine-aspartic proteases) are intracellular cysteine protease enzymes (such as caspase-3 and -7) that are involved in the regulation of programmed cell death (apoptosis) to maintain cellular homeostasis during development. Caspases are activated by initiator caspases, like caspase-9. Their activation will sequentially activate other executioner caspases which in turn result in enhanced cellular degradation and apoptotic morphological changes [3] [4]. Deregulation and inhibition of apoptosis is a known mechanism of cancerization and cancer progression. As survivin mainly functions as an anti-apoptotic protein, its expression in tumor cells was found to be correlated with aggressiveness and adverse clinical prognosis making it a promising biomarker or an indicator of tumor aggressiveness and/or response to therapy [5] [6].

Survivin down regulates p53 [7]. Overexpression of survivin may overcome checkpoints of the cell cycle and result in increased mitosis and lead to the trans- 
formation to malignant cells [8] [9] [10].

\section{Survivin and Bladder Cancer}

studies relate survivin to survivin overexpression is strongly predictive of recurrence, progression specially mortality in bladder cancer and the malignant progression of urothelial carcinoma of the urinary bladder [11] [12]. Other studies showed that number of positive tumor cells increasing with the grade of the tumor [13]. other studies detect urine survivin sensitivity in comparison with the cystoscopy as a standard method but results showed less than $80 \%$ sensitivity [14] [15].

\section{Survivinin Breast Cancer}

Positive expression of survivin in breast cancer predicted a significantly higher risk of disease recurrence and is shown to be associated with lymph node metastasis $(\mathrm{P}$ value $=0.01)[16]$. The rate of survivin expression seems to correlate with the sensitivity of survivin detection methods. In one study using survivin immunohistochemistry, survivin was expressed in $65.3 \%$ (55.2\% - 90.0\%) of breast cancer samples while survivin mRNA detection using RT-PCR was identified in 93.6\% (90\% - 97\%) of cases. The same study showed association of survivin expression with HER2 overexpression, vascular endothelial growth factor (VEGF) and, urokinase plasminogen activator (uPA)/PAI-1 [17].

A study from Egypt investigated the expression of survivin in correlation with the clinicopathological parameters, proliferation and molecular classification of breast carcinoma. In that study, survivin expression (detected in $78.5 \%$ of breast carcinomas) was related to tumor size, high histologic grade, lymph node metastases, advanced tumor stage, MIB-1 index and negative estrogen/progesterone receptor status. Notably, the subcellular localization of survivin significantly related to histologic grade, stage and lymph node involvement [18] [19]. In another study on 420 non-metastatic breast cancer tissue samples using the ELISA method, a high survivin expression was detected in $90 \%$ of cases and indicated a significantly poor prognosis on long term follow up [19].

\section{Survivin Expression in Head and Neck Cancer}

Different types of head and neck neoplasms have been studied for survivin expression in different studies. Expression of survivin and COX2 was related to the ability of invasion and cancerization in ameloblastoma [20] [21]. Overexpression of these 2 markers in oral mucosal premalignant lesions suggests a role in early stages of oral carcinogenesis [22]. Another study handled localization and prognostic value of nuclear and cytoplasmic survivin expression in the pre-therapeutic biopsies of 71 oral and oropharyngeal squamous cell carcinoma (OSCC) patients. Their results indicated that nuclear versus cytoplasmic survivin correlated with prognostic outcome. Cytoplasmic localization of survivin is also considered a potential therapeutic strategy [23]. Cases of oral SCC together with distant metastatic lesions were 
analyzed for expression of survivin by immunohistochemistry and Western blotting. Out of the 91 cases (82.7\%) of primary SCC and all metastases (seven cases, $100 \%$ ) were positive for survivin expression, there was no significant correlation between survivin expression and age, sex, tumor size, and the presence of lymph node and distant metastases. Survivin expression was higher in less differentiated tumors and was prognostically significant $(\mathrm{P}<0.05)[24]$.

Correlation between survivin mRNA expression and clinicopathologic features or prognosis of OSCC patients was analyzed. Small interfering RNA technology was used to detect and decrease cancerous cells expression of survivin and detect the effect on its sensitivity to chemotherapeutic drugs [25].

\section{Survivin and Digestive Tract Tumors}

The role of survivin in colonic tissue transformation of dysplasia low dysplasia to high dysplasia with P53 and B catenin was studied and results showed that positivity of survivin is raised by six to twelve folds in tumor cells [26] [27].

Regarding prognosis of recurrent colorectal carcinoma surviving considered as patients with negative survivin tumors had a five-year survival rate of $94.4 \%$ compared with $44.8 \%$ for patients with Survivin positive tumors [28].

(New Gene therapy for colon cancer by adeno-associated viral vector-mediated transfer of survivin Cys84Ala mutant gastro was studied and concluded that the use of AAV-mediated survivin mutant (Cys84Ala) is a promising strategy in colon cancer gene therapy) [29].

Other Studies aimed downregulation of survivin by induction of EPR-1 cDNA noticed a decrease in tumor growth and increased response to anticancer agents used for treatment of colon cancer [30]. Finally, the overall survival rate is decreased in those studied for showed positive survivin [31].

\section{Survivin and Genital Tract Tumors}

No survivin mRNA was expressed in all normal ovarian specimens, while it appeared in $73 \%$ of ovarian carcinomas, $47 \%$ of borderline ovarian carcinomas and $19 \%$ of benign ovarian tumors study suggest that survivin is associated with progression of ovarian carcinoma [32].

A retrospective review on Survivin status affects prognosis and chemosensitivity in epithelial ovarian was done on 90 patients with a median follow-up time of 51 months. The reverse transcription-polymerase chain reaction and flow cytometry were applied to detect survivin expression levels and cell apoptotic percentages. Results showed that cytoplasmic survivin protein expression is an independent molecular marker for prognosis. Sequence-specific shRNA targeting survivin can effectively suppress survivin expression, enhance apoptosis, and increase the sensitivity of ovarian cancer cells to paclitaxel but not to cisplatin [33].

Studies on endometrial carcinoma associated with PTEN abnormalities found that PTEN may interfere with the process of apoptosis and by promoting survivin expression [34]. Data indicate that a survivin-specific immune response may 
be induced spontaneously in patients, further fortifying the eligibility of survivin as an immunotherapeutic target [35].

\section{Survivin Expression in Lymph Nodes}

survivin over expression might be a poor prognostic factor for patients with NHL. However, more large-scale studies are needed to confirm these findings [36] [37]. Survivin suggested as an attractive target for new anti-cancer intervention of NHL and vector-based survivin-shRNA could clearly reduce the expression of survivin and induce cell apoptosis and growth inhibition of malignant cells [36].

\section{Survivin and Renal Cell Carcinoma}

Survivin was suggested as a prognostic marker in renal cell carcinoma. Expression was correlated with prognosis and clinicopathological features, and it could be used in the future as a biomarker for in therapy after more comprehensive studies [38].

\section{Survivin and Hepatocellular Carcinoma}

Survivin expression correlates with nuclear and histologic grade, microvascular invasion, increased mitotic figures, local recurrence, and poor prognosis. RT-PCR detection test for survivin along with immunohistochemistry of 20 cases of hepatocellular carcinoma and one case diagnosed as intrahepatic cholangiocarcinoma. Low levels of Survivin mRNA can be detected in normal and liver tissue [39]. Overexpression of the protein is associated with positive nuclear p53 nuclear staining [40]. The concentration of the protein may reflect the prognosis of the case but this is still needs more studies [41]. Two survivin scoring methods-topoisomerase II $\alpha$ nuclear labelling index (LI) and tumor differentiation-were analyzed by researchers for specificity results showed that Survivin nuclear LI correlated significantly with tumor cell proliferation [42].

\section{Survivin in Pancreatic Cancer}

A study correlated survivin mRNA, promoter's expression and radio sensitivity of the tumors showing a very promising result regarding radio-sensitivity and survivin inhibitors treatment usage and improvement of prognosis [43] [44] [45] [46].

Targeting survivin as an upstream regulator of mitochondrial dependent apoptosis, not only enhance apoptosis but also suppress angiogenesis [47].

\section{Survivin in Head and Neck Tumors}

Survivin expression in head and neck squamous cell carcinoma (HNSCC) as assessed by immunohistochemical staining and western blot and then compared with normal tissue was significantly associated with loss of differentiation in tumors and in that study, Bcl-XL was associated with nodal metastasis $(\mathrm{P}<0.001)$ [48].

Furthermore, Oxaliplatin treatment for HNSCC was studied in radioresistant 
cases with high survivin levels and found to be effective in reducing the resistant to radiation therapy [49].

\section{Conclusion}

Survivin is an important biomarker in diverse types of malignant neoplasms originating in different organs. Correlation of survivin expression with adverse tumor characteristics and less favorable patient's outcome indicates the importance of including survivin in the biomarker panel used to evaluate malignancies with therapeutic and prognostic implications.

\section{Acknowledgements}

I am grateful to Prof Abbas Agaimy for assistance in improving the manuscript significantly.

\section{References}

[1] Altieri, D.C. (1994) Splicing of Effector Cell Protease Receptor-1 mRNA Is Modulated by an Unusual Retained Intron. Biochemistry, 33, 13848-13855. https://doi.org/10.1021/bi00250a039

[2] Cohen, C., Lohmann, C.M., Cotsonis, G., Lawson, D. and Santoianni, R. (2003) (ASCP) Survivin Expression in Ovarian Carcinoma: Correlation with Apoptotic Markers and Prognosis. Modern Pathology, 16, 574-583. https://doi.org/10.1097/01.MP.0000073868.31297.B0

[3] Wheatley, S.P. and McNeish, I.A. (2005) Survivin: A Protein with Dual Roles in Mitosis and Apoptosis. International Review of Cytology, 247, 35-88. https://doi.org/10.1016/S0074-7696(05)47002-3

[4] Thornberry, N.A. and Lazebnik, Y. (1998) Caspases: Enemies within. Science, 281, 1312-1316. https://doi.org/10.1126/science.281.5381.1312

[5] Sollberger, G., Strittmatter, G.E., Garstkiewicz, M., Sand, J. and Beer, H.-D. (2014) Caspase-1: The Inflammasome and Beyond. Innate Immunity, 20, 115-125. https://doi.org/10.1177/1753425913484374

[6] Altieri, D.C. (2003) Survivin, Versatile Modulation of Cell Division and Apoptosis in Cancer. Oncogene, 22, 8581-8589. https://doi.org/10.1038/sj.onc.1207113

[7] Wang, Z., Fukuda, S. and Pelus, L.M. (2004) Survivin Regulates the p53 Tumor Suppressor Gene Family. Oncogene, 23, 8146-8153. https://doi.org/10.1038/sj.onc.1207992

[8] Sah, N.K., Khan, Z., Khan, G.J. and Bisen, P.S. (2006) Structural, Functional and Therapeutic Biology of Survivin. Cancer Letters, 244, 164-171. https://doi.org/10.1016/j.canlet.2006.03.007

[9] Fortugno, P., Wall, N.R., Giodini, A., O’Connor, D.S., Plescia, J., et al. (2002) Survivin Exists in Immunochemically Distinct Subcellular Pools and Is Involved in Spindle Microtubule Function. Journal of Cell Science, 115, 575-585.

[10] Li, F. and Ling, X. (2006) Survivin Study: An Update of "What Is the Next Wave"? Journal of Cellular Physiology, 208, 476-486. https://doi.org/10.1002/jcp.20634

[11] Yin, W., Chen, N., Zhang, Y., et al. (2006) Survivin Nuclear Labeling Index: A Superior Biomarker in Superficial Urothelial Carcinoma of Human Urinary Bladder. Modern Pathology, 19, 1487-1497. https://doi.org/10.1038/modpathol.3800675 
[12] Yildirim, U., Erdem, H., Kayikci, A., Sahin, A.F., Uzunlar, A.K. and Albayrak, A. (2010) Cyclooxygenase-2 and Survivin in Superficial Urothelial Carcinoma of the Bladder and Correlation with Intratumoural Microvessel Density. Journal of International Medical Research, 38, 1689-1699. https://doi.org/10.1177/147323001003800514

[13] Margulis, V., Lotan, Y. and Shariat, S. (2008) Survivin: A Promising Biomarker for Detection and Prognosis of Bladder Cancer. World Journal of Urology, 26, 59-65. https://doi.org/10.1007/s00345-007-0219-y

[14] Jeon, C., Kim, M., Kwak, C., Kim, H.H. and Ku, J.H. (2013) Prognostic Role of Survivin in Bladder Cancer: A Systematic Review and Meta-Analysis. PLoS One, 8, e76719. https://doi.org/10.1371/journal.pone.0076719

[15] Vriesema, J.L., Poucki, M.H., Kiemeney, L.A. and Witjes, J.A. (2000) Patient Opinion of Urinary Tests versus Flexible Urethra Cystoscopy in Follow-Up Examination for Superficial Bladder Cancer: A Utility Analysis. Urology, 56, 793-797. https://doi.org/10.1016/S0090-4295(00)00777-9

[16] Li, Y., Ma, X., Wu, X., Liu, X. and Liu, L. (2014) Prognostic Significance of Survivin in Breast Cancer: Meta-Analysis. The Breast Journal, 20, 514-524. https://doi.org/10.1111/tbj.12303

[17] Jha, K., Shukla, M. and Pandey, M. (2012) Survivin Expression and Targeting in Breast Cancer. Surgical Oncology, 21, 125-131. https://doi.org/10.1016/j.suronc.2011.01.001

[18] Youssef, N.S., Hewedi, I.H. and Abd Raboh, N.M. (2008) Immunohistochemical Expression of Survivin in Breast Carcinoma: Relationship with Clinicopathological Parameters, Proliferation and Molecular Classification. Journal of the Egyptian National Cancer Institute, 20, 348-357.

[19] Ryan, B.M., Konecny, G.E., Kahlert, S., Wang, H.J., Untch, M., Meng, G., Pegram, M.D., Podratz, K.C., Crown, J., Slamon, D.J. and Duffy, M.J. (2006) Survivin Expression in Breast Cancer Predicts Clinical Outcome and Is Associated with HER2, VEGF, Urokinase Plasminogen Activator and PAI-1. Annals of Oncology, 17, 597-604. https://doi.org/10.1093/annonc/mdj121

[20] Li, L., Zhang, X.L., Wang, P. and Liu, Y. (2014) Expression of Survivin in Ameloblastoma and Its Clinical Significance. Shanghai Journal of Stomatology, 23, 481-484.

[21] Khan, Z., Tiwari, R.P., Mulherkar, R., Sah, N.K., Prasad, G., Shrivastava, B.R. and Bisen, P.S. (2009) Detection of Survivin and p53 in Human Oral Cancer: Correlation with Clinicopathologic Findings. Head Neck, 31, 1039-1048.

[22] Uzawa, T.C.K., Shibahara, T., Yokoe, H., Noma, H. and Tanzawa, H. (2003) Expression of an Inhibitor of Apoptosis, Survivin, in Oral Carcinogenesis. Journal of Dental Research, 82, 607-611. https://doi.org/10.1177/154405910308200807

[23] Engels, K., Knauer, S.K., Metzler, D., Simf, C., Struschka, O., Bier, C., Mann, W., Kovács, A.F. and Stauber, R.H. (2007) Dynamic Intracellular Survivin in Oral Squamous Cell Carcinoma: Underlying Molecular Mechanism and Potential as an Early Prognostic Marker. The Journal of Pathology, 211, 532-540.

[24] Lo Muzio, L., Pannone, G., Staibano, S., Mignogna, M.D., Rubini, C., Mariggiò, M.A., Procaccini, M., Ferrari, F., De Rosa, G. and Altieri, D.C. (2003) Survivin Expression in Oral Squamous Cell Carcinoma. British Journal of Cancer, 89, 2244-2248.

[25] Su, L., Wang, Y., Xiao, M., Lin, Y. and Yu, L. (2010) Up-Regulation of Survivin in Oral Squamous Cell Carcinoma Correlates with Poor Prognosis and Chemoresistance. Oral and Maxillofacial Pathology, 110, 484-491.

[26] Kawasaki, H., Toyoda, M., Okuda, H.S.J., Watanabe, I., et al. (2001) Expression of 
Survivin Correlates with Apoptosis, Proliferation, and Angiogenesis during Human Colorectal Tumorigenesis. American Cancer Society, 91, 2026-2032.

[27] Kim, P.J., Plescia, J., Clevers, H., Fearon, E.R. and Altieri, D.C. (2003) Survivin and Molecular Pathogenesis of Colorectal Cancer. The Lancet, 362, 205-209.

[28] Sarelaa, A.I., Macadama, R.C., Farmerya, S.M., Markhamb, A.F. and Guilloua, P.J. (2000) Expression of the Antiapoptosis Gene, Survivin, Predicts Death from Recurrent Colorectal Carcinoma. Gut, 46, 645-650. https://doi.org/10.1136/gut.46.5.645

[29] Tu, S.P., Cui, J.T., Liston, P., et al. (2004) Gene Therapy for Colon Cancer by Adeno-Associated Viral Vector-Mediated Transfer of Survivin Cys84Ala Mutant. Gastroenterology, 128, 361-375.

[30] Yamamotoa, T., Manomeb, Y., Nakamuraa, M. and Tanigawaa, N. (2002) Downregulation of Survivin Expression by Induction of the Effector Cell Protease Receptor-1 Reduces Tumor Growth Potential and Results in an Increased Sensitivity to Anticancer Agents in Human Colon Cancer. European Journal of Cancer, 38, 2316-2324.

[31] Kawasaki, H., Altieri, D.C., Lu, C.-D., Toyoda, M., Tenjo, T. and Tanigawa, N. (1998) Inhibition of Apoptosis by Survivin Predicts Shorter Survival Rates in Colorectal Cancer. Cancer Research, 58, 5071-5074.

[32] Liguang, Z., Peishu, L., Hongluan, M., Hong, J., Rong, W., Wachtel, M.S. and Frezza, E.E. (2007) Survivin Expression in Ovarian Cancer. Experimental Oncology, 29, 121-125.

[33] Chen, L., Liang, L., Yan, X., Liu, N., Gong, L., Pan, S., Lin, F., Zhang, Q., Zhao, H. and Zheng, F. (2013) Survivin Status Affects Prognosis and Chemosensitivity in Epithelial Ovarian Cancer. International Journal of Gynecological Cancer, 23, 256-263. https://doi.org/10.1097/IGC.0b013e31827ad2b8

[34] Pallares, J., Martínez-Guitarte, J.L., Dolcet, X., Llobet, D., Rue, M., Palacios, J., Prat, J. and Matias-Guiu, X. (2005) Survivin Expression in Endometrial Carcinoma: A Tissue Microarray Study with Correlation with PTEN and STAT-3. International Journal of Gynecological Pathology, 24, 247-253

[35] Vanderstraeten, A., Everaert, T., Van Bree, R., et al. (2015) In Vitro Validation of Survivin as Target Tumor-Associated Antigen for Immunotherapy in Uterine Cancer. Journal of Immunotherapy, 38, 239-249.

[36] Congmin, G., Mu, Z., Yihui, M. and Hanliang, L. (2006) Survivin-An Attractive Target for RNAi in Non-Hodgkin's Lymphoma, Daudi Cell Line as a Model. Leukemia \& Lymphoma, 47, 1941-1948. https://doi.org/10.1080/10428190600725354

[37] He, C., Liu, Z., Ji, J. and Zhu, H. (2015) Prognostic Value of Survivin in Patients with Non-Hodgkin's Lymphoma: A Meta-Analysis. International Journal of Clinical and Experimental Medicine, 8, 5847-5854.

[38] Xie, Y., Ma, X., Gu, L., Li, H., Chen, L., et al. (2016) Prognostic and Clinicopathological Significance of Survivin Expression in Renal Cell Carcinoma: A Systematic Review and Meta-Analysis. Scientific Reports, 6, Article No. 29794.

[39] Fields, A.C., Cotsonis, G., Sexton, D., Santoianni, R. and Cohen, C. (2004) Survivin Expression in Hepatocellular Carcinoma: Correlation with Proliferation, Prognostic Parameters, and Outcome. Modern Pathology, 17, 1378-1385. https://doi.org/10.1038/modpathol.3800203

[40] Kannangai, R., Wang, J., Liu, Q.Z., Sahin, F. and Torbenson, M. (2005) Survivin Overexpression in Hepatocellular Carcinoma Is Associated with p53 Dysregulation. International Journal of Gastrointestinal Cancer, 35, 53-60. https://doi.org/10.1385/IJGC:35:1:053 
[41] Montorsi, M., Maggioni, M., Falleni, M., Pellegrini, C., Donadon, M., Torzilli, G., Santambrogio, R., Spinelli, A., Coggi, G. and Bosari, S.H. (2007) Survivin Gene Expression in Chronic Liver Disease and Hepatocellular Carcinoma. Hepatogastroenterology, 54, 2040-2044.

[42] Hasby, E.A. and Mokhtar, M.A. (2010) Survivin Immunohistochemical Expression in Hepatocellular Carcinoma: Correlation with Tumor Differentiation and Proliferation. Arab Journal of Gastroenterology, 11, 141-148.

[43] Kami, K., Doi, R., Koizumi, M., Toyoda, E., Mori, T., Ito, D., Fujimoto, K., Wada, M., Miyatake, S. and Imamura, M. (2004) Survivin Expression Is a Prognostic Marker in Pancreatic Cancer Patients. Surgery, 136, 443-448. https://doi.org/10.1016/j.surg.2004.05.023

[44] Waligórska-Stachura, J., Jankowska, A., Waśko, R., Liebert, W., et al. (2012) Survivin Prognostic Tumor Biomarker in Human Neoplasms-Review. Ginekologia Polska, 83, 537-540.

[45] Rödel, F., Sprenger, T., Kaina, B., Liersch, T., Rödel, C., Fulda, S. and Hehlgans, S. (2012) Survivin as a Prognostic/Predictive Marker and Molecular Target in Cancer Therapy. Current Medicinal Chemistry, 19, 3679-3688.

[46] Rödel, F., Reichert, S., Sprenger, T., Gaipl, U.S., Mirsch, J., Liersch, T., Fulda, S. and Rödel, C. (2011) The Role of Survivin for Radiation Oncology: Moving beyond Apoptosis Inhibition. Current Medicinal Chemistry, 18, 191-199. https://doi.org/10.2174/092986711794088362

[47] Blanc-Brude, O.P., Mesri, M., Wall, N.R., et al. (2003) Therapeutic Targeting of the Survivin Pathway in Cancer: Initiation of Mitochondrial Apoptosis and Suppression of Tumor-Associated Angiogenesis. Clinical Cancer Research, 9, 2683-2692.

[48] Sharma, H., Sen, S., Mathur, M., Bahadur, S. and Singh, N. (2004) Combined Evaluation of Expression of Telomerase, Survivin, and Anti-Apoptotic bcl-2 Family Members in Relation to Loss of Differentiation and Apoptosis in Human Head and Neck Cancers. Head and Neck, 26, 733-740.

[49] Khan, Z., Khan, N., Tiwari, R.P., Patro, I.K., Prasad, G.B. and Bisen, P.S. (2010) Down-Regulation of Survivin by Oxaliplatin Diminishes Radioresistance of Head and Neck Squamous Carcinoma Cells. Radiotherapy and Oncology, 96, 267-273. https://doi.org/10.1016/j.radonc.2010.06.005 


\section{Abbreviations}

BIRC5: Baculoviral inhibitor of apoptosis repeat-containing 5

HER2: Human epidermal growth factor receptor 2

VEGF: Vascular endothelial growth factor

PAI-1: Plasminogen activator inhibitor-1

MIB-1: Mindbomb E3 ubiquitin protein ligase 1

COX2: Cyclooxygenase 2

OSCC: Oral Squamous Cell Carcinoma

SCC: Squamous Cell Carcinoma

AAV: Adeno-associated virus

EPR-1 cDNA: Effector cell protease receptor 1 complementary DNA

PTEN: Phosphatase and tensin homolog

NHL: Non-Hodgkin lymphoma

Bcl-2: B cell lymphoma 2

Bcl-XL: B cell lymphoma extra large 